\title{
Computational Study to Predict the Free-Surface Flow over Non-uniform Stepped Spillway Using ANSYS-CFX
}

\author{
Shawnm M. Saleh*, Sarhang M. Husain \\ Department of Water Resources, College of Engineering, Salahaddin University, Erbil, Kurdistan Region, Iraq
}

\author{
${ }^{*}$ Corresponding author: \\ Shawnm M. Saleh, \\ Department of Water \\ Resources, \\ College of Engineering, \\ Salahaddin University, Erbil, \\ Kurdistan Region, Iraq. \\ E-mail: shawnm.saleh@ \\ su.edu.krd
}

Received: 05 January 2020

Accepted: 08 March 2020

Published: 30 June 2020

DOI

10.25156/pti.v10n1y2020.pp43-50

\begin{abstract}
A B S T R A C T
Using stepped chutes as a structure for controlling flood discharges is applicable for long time. Measuring the depth of flow over that structure is essential for designing of the side walls. The aim of this paper is to determine the free-surface that flows on spillway equipped with non-uniform step sizes. For that purpose, the two-dimensional software package code of ANSYS-CFX has been utilized to run eight configurations of two moderate slopes $(1 \mathrm{~V}: 2 \mathrm{H}$ and $1 \mathrm{~V}: 2.5 \mathrm{H})$ and for four different discharges $1 \leq \mathrm{d}_{\mathrm{c}} /$ $h_{s} \leq 2.2$ to determine the effect of flow discharges, chute slopes, and step heights on the position of free surface along the structure over non-uniform stepped cascade. The hexahedral grid size of $0.015 \mathrm{~m}$ is selected with inflation technique close to the walls. In addition, the renormalized group of $\mathrm{k}-\varepsilon$ (RNG) turbulence model is implemented and the numerical volume of fluid software is employed. The results show smoother stream for higher discharges, and the free-surface drops when the slope of chutes increases. Moreover, it is found that the step size has insignificant effect on the depth of water. The results of this study are important because they provide new insight in improving the design of stepped spillways. It is recommended to perform more investigations to evaluate their effectiveness in other flow parameters including pressure distribution and energy dissipation rates.
\end{abstract}

Keywords: Volume of fluid; Numerical simulation; Free-surface flow; Non-uniform stepped spillway; ANSYS-CFX

\section{INTRODUCTION}

Many engineers use the step falls for designing spillways because of its relatively high capability of losing the overflowing energy. Steps of various geometries and configurations are fitting the $\mathrm{D} / \mathrm{S}$ slope of these spillways, which are usually rough enough to increase the turbulence rate. This leads not only to enhance the amount of energy dissipation rate but also improve the self-aeration mechanism much better than the other kind of spillways (Chanson, 1994, Chamani, 1998). In fact, these reduce the potential of both: (1) Needing stilling basins at the end of the structure and (2) installing air diffusers inside the structure and hence the cost of this hydraulic structure is considerably decreased. Further spreading the technology of roller compacted concrete has increased the interest on this type of spillway (Boes and Hager, 2003b).

Two main types of flow regimes happen over stepped spillways when the water passes over-them, which are known as nappe and skimming flow regime. Transition flow regime condition occurs when the flow regime changes from nappe to skimming (Chanson, 1996). Boundary layer starts at the upstream of the spillway and it meets with the water surface at a point which is termed as inception point where air entrainment initiates (Chanson, 1994). The flow is smooth upstream of that point, while its wavy due to the mixture of air and water at the bottom of the inception point (Chakib and Mohammed, 2015).

The free-surface profile was studied by many investigators using both experimental and numerical methods. Experimentally, the water surface profile over uniform stepped spillway with step height of $0.08 \mathrm{~m}$ measured by Matos et al., 1999, for chute slope 1V:0.75H and for three different discharges. Their results showed a wavy pattern over the spillway, and indicated that the waves decrease with increasing the flow rate. Khalaf et al., 2014. also measured the water surface profile over stepped cascade with number of steps 3, 5, and 7. According to their study, the uniformity of free-surface increase when $\mathrm{X} / \mathrm{P}>3$ in which, $\mathrm{X}$ is the distance from the crest and $\mathrm{P}$ is the spillway height. Felder, 2013, worked out experiments on non-uniform stepped spillways to find the free-surface profile. The geometry of his experimental model consisted of two steps of $h_{\mathrm{s}}=0.05 \mathrm{~m}$ followed by one step of $h_{s}=0.1 \mathrm{~m}$ filling the surface of a chute of $\mathrm{D} / \mathrm{S}$ slope of $1 \mathrm{~V}: 2 \mathrm{H}$ with the crest length of $0.62 \mathrm{~m}$ for flow discharge $\mathrm{q}=0.116 \mathrm{~m}^{2} / \mathrm{s}$. The measurements revealed that the free surface was highly fluctuating close to the point of inception and wavy pattern downstream of 
the inception point due to the mixture of air to the water. However, he reported that this flow behavior was almost disappeared when the flow discharge is large. In addition, he observed that the flow depth was decreased with increasing the distance between the crest and the point of inception and then was increased toward the end because of airentrainment and flow depth bulking (Chanson, 1998). The experimental of the latter investigation was considered to verify the results predicted in the current work. For saving cost and time numerical simulation method have been commonly used by many authors to study, the flow behavior of stepped spillway. Tabbara et al., 2005, used ADINA software for predicting the surface profile over uniform stepped spillway. Husain et al., 2014, applied SPH method for drawing the free-surface profile over horizontal steps. Flow-3D was implemented by Bombardelli et al., 2011, Valero and Bung, 2015, for steep and moderate slopes, respectively, over horizontal and uniform step spillways for calculating the water surface profile. They also realized that the flow over spillway is wavy and strong fluctuations where observed close to the inception point. The same results obtained by Lucio, 2015, who used Flow-3D for moderate slope and $\mathrm{Q}=18 \mathrm{l} / \mathrm{s}$. He stated that the flow depth increased downstream of the inception point due to the mixture air with water and that higher flow depth was predicted for larger discharge. Van Alwon et al., 2017, determined the location of free-surface over uniform step spillway with $\theta=45^{\circ}$ by utilizing ANSYS-FLUENT with two different methods (VOF and Eulerian) and found that VOF cannot show the air entrainment. While, Bentalha and Habi, 2019, found good agreement between the experimental data and that obtained by numerical code ANSYS-FLUENT using VOF method in predicting the free-surface profile. ANSYS-CFX was employed by Jalil and Hussein, 2017, for measuring the water surface over stepped spillways for slope $(1 \mathrm{~V}: 1 \mathrm{H}$ and $1 \mathrm{~V}: 2 \mathrm{H})$ and they found acceptable agreement between the computational data and experimental data. We observed that numerous studies are available in the literature for uniform, steps with different geometries such as pooled (Li and Zhang, 2018), micro roughness elements (André and Schleiss, 2004) inclined (Chinnarasri and Wongwises, 2004), longitudinal vanes (Gonzalez, 2005), and other configurations. However, information about the stepped spillway with non-uniform step height is still limited.

The main objective of this study is to determine the location of free-surface over non-uniform stepped spillways by numerical ANSYS-CFX code for different skimming flow discharges $\left(1 \leq \mathrm{d}_{\mathrm{c}} / \mathrm{h}_{\mathrm{s}} \leq 2.2\right)$ where $\mathrm{d}_{\mathrm{c}}$ and $\mathrm{h}_{\mathrm{s}}$ are the critical depth and step height, respectively, on two moderate slopes (1 V:2H and $1 \mathrm{~V}: 2.5 \mathrm{H})$, with different step heights using various arrangements. The results of this study are important in improving the design aspects of stepped spillway.

\section{METHODOLOGY}

The software package used in the current study is $2 \mathrm{D}$ ANSYS-CFX code with one unit extrudes to predict the free-surface profile over stepped spillway with non-uniform step sizes. For simulating two-dimensional flow, the partial differential equations or continuity and momentum equations are as follows:

Continuity equation:

$$
\frac{\partial u}{\partial x}+\frac{\partial v}{\partial y}+\frac{\partial w}{\partial z}=0
$$

In which:

$u$ Is the water velocity in the direction of $x(\mathrm{~m} / \mathrm{s})$

$v$ Is the water velocity in the direction of $y(\mathrm{~m} / \mathrm{s})$

$w$ Is the water velocity in the direction of $z(\mathrm{~m} / \mathrm{s})$.

Momentum equation in $X$ direction:

$$
\begin{aligned}
& \frac{\partial(\rho u)}{\partial t}+\frac{\partial\left(\rho u^{2}\right)}{\partial x}+\frac{\partial(\rho u v)}{\partial y}+\frac{\partial(\rho u v)}{\partial z} \\
& =\rho g_{x}-\frac{\partial p}{\partial x}+\mu\left(\frac{\partial^{2} u}{\partial x^{2}}+\frac{\partial^{2} u}{\partial y^{2}}+\frac{\partial^{2} u}{\partial z^{2}}\right)
\end{aligned}
$$

Momentum equation in $Y$ direction:

$$
\begin{aligned}
& \frac{\partial(\rho v)}{\partial t}+\frac{\partial(\rho v u)}{\partial x}+\frac{\partial\left(\rho v^{2}\right)}{\partial y}+\frac{\partial(\rho v w)}{\partial z} \\
& =\rho g_{y}-\frac{\partial p}{\partial y}+\mu\left(\frac{\partial^{2} v}{\partial x^{2}}+\frac{\partial^{2} v}{\partial y^{2}}+\frac{\partial^{2} v}{\partial z^{2}}\right)
\end{aligned}
$$

Momentum equation in $Z$ direction:

$$
\begin{aligned}
& \frac{\partial(\rho w)}{\partial t}+\frac{\partial(\rho w u)}{\partial x}+\frac{\partial(\rho w v)}{\partial y}+\frac{\partial\left(\rho w^{2}\right)}{\partial z} \\
& =\rho g_{z}-\frac{\partial p}{\partial z}+\mu\left(\frac{\partial^{2} w}{\partial x^{2}}+\frac{\partial^{2} w}{\partial y^{2}}+\frac{\partial^{2} w}{\partial z^{2}}\right)
\end{aligned}
$$

Where:

$\varrho=$ density of water $(\mathrm{kg} / \mathrm{m} 3)$

$\mu=$ viscosity of water $(\mathrm{kg} /$ (s.m))

$g_{x}=$ acceleration due to gravity in the direction of $x\left(\mathrm{~m} / \mathrm{s}^{2}\right)$

$g_{y}=$ acceleration due to gravity in the direction of $y\left(\mathrm{~m} / \mathrm{s}^{2}\right)$

$g_{z}=$ acceleration due to gravity in the direction of $z\left(\mathrm{~m} / \mathrm{s}^{2}\right)$ 
$\frac{\partial p}{\partial x}=$ pressure differentiation in the direction of $x(\mathrm{~Pa} / \mathrm{m})$ $\partial x$

$\frac{\partial p}{\partial y}=$ pressure differentiation in the direction of $y(\mathrm{~Pa} / \mathrm{m})$

$\frac{\partial p}{\partial z}=$ pressure differentiation in the direction of $z(\mathrm{~Pa} / \mathrm{m})$.

\section{Validation Process}

As mentioned above, the computational 2D ANSYSCFX code with one unit extrude was calibrated versus the experimental results of Felder, 2013, in terms of the position of free-surface over non-uniform steps by Saleh and Husain, 2019. They stated that both the computational and experimental data were in good agreement. Indeed, this motivated us to apply this software with the same numerical tools, grid size, and mesh type to determine the distribution of free-surface profile over eight numerical configurations of non-uniform stepped spillway with different configurations and chute slopes.

\section{Numerical Modeling}

The techniques applied by Saleh and Husain, 2019, to validate the laboratory data are implemented in this study to generate and run 32 models of eight different configurations with two different slopes and four discharges typically in skimming flow regime.

\section{Model Geometries}

AUTOCAD software was utilized for drawing all the geometries. For all models examined in current work, the height of the spillway are fixed at $1.28 \mathrm{~m}$ and the crest of the spillway selected as horizontal with $0.62 \mathrm{~m}$ length. The geometries are shown in Figures 1 and 2 for slope 1V:2H

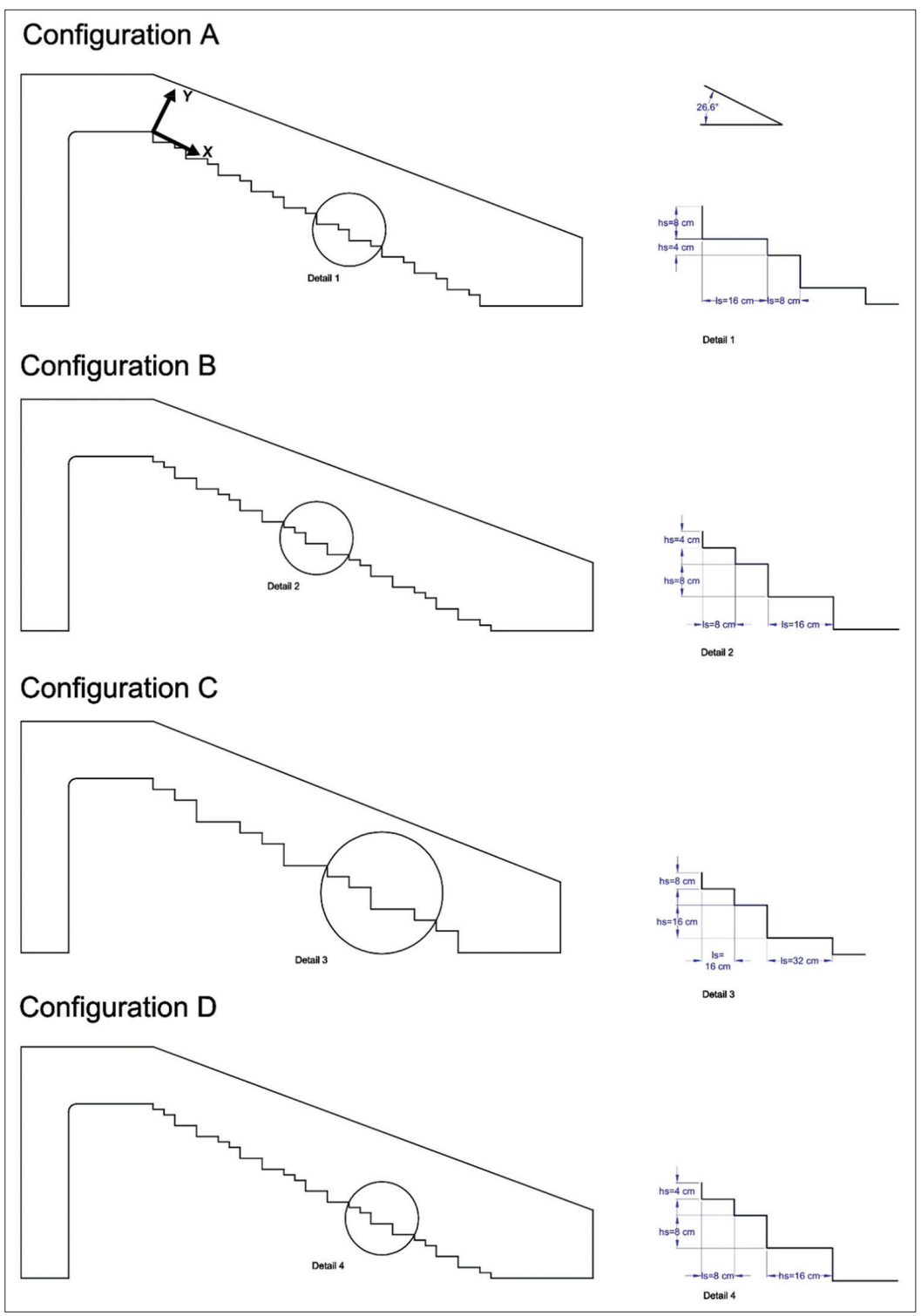

Figure 1: Details of step configurations for slope $\theta=26.6^{\circ}$ 


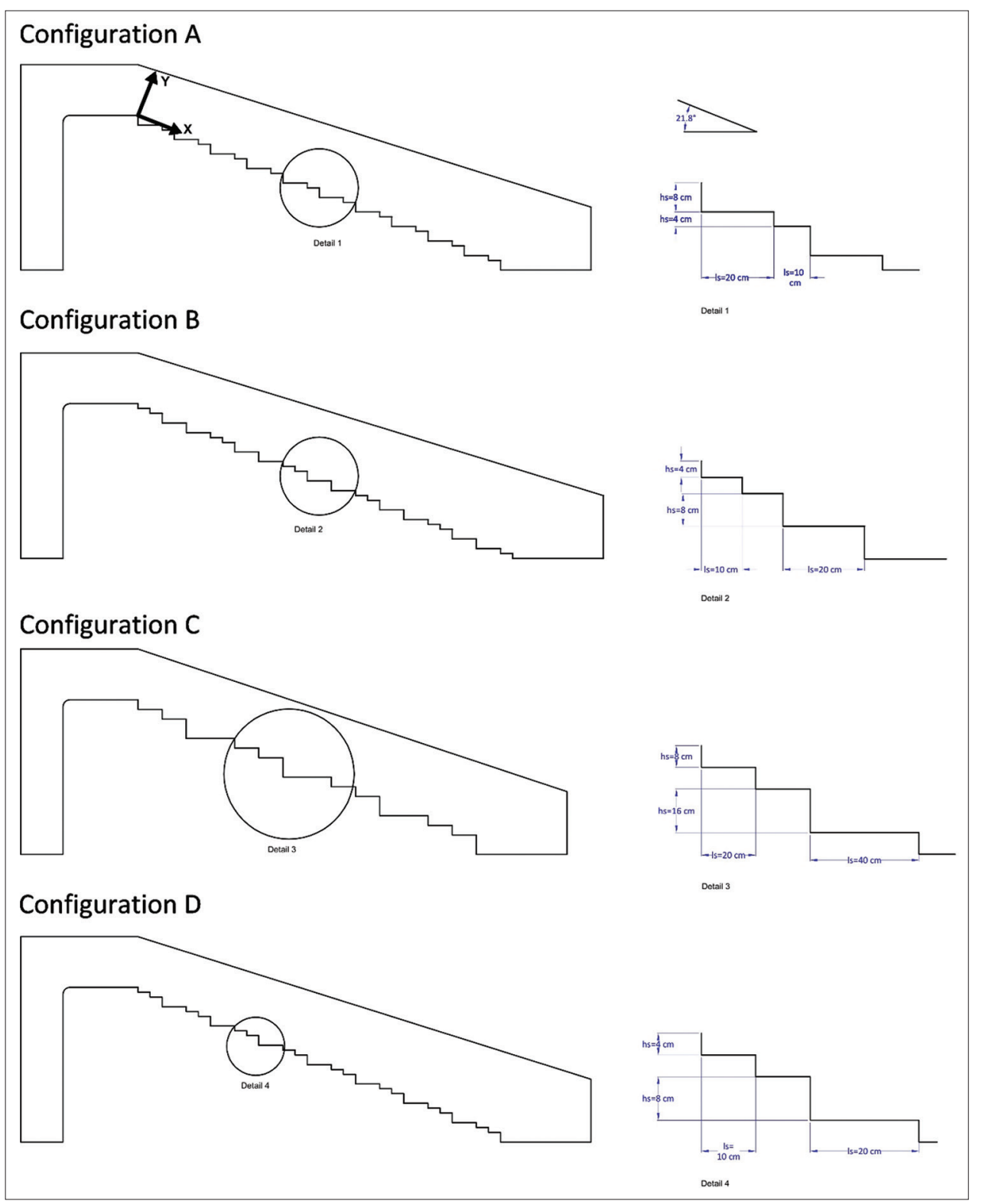

Figure 2: Details of step configurations for slope $\theta=21.8^{\circ}$

and $1 \mathrm{~V}: 2.5 \mathrm{H}$, respectively, with details of each arrangement. The geometries then exported to ANSYS workbench for applying other techniques and running them.

\section{Mesh Techniques}

Following to Saleh and Husain, 2019, the hexahedral mesh type with grid size $0.015 \mathrm{~m}$ as it provided results with acceptable accuracy relatively short computational time. In addition, inflation technique supported by ANSYS-CFX is applied close to the walls in an attempt to improve the accuracy of the computational results. In addition, in this investigation the value of 32.5 is estimated for $\mathrm{y}+$ value which is defined as a non-dimensional wall distance from wall bounded flow, as it smooth's out the percentage of error greatly (Salim and Cheah, 2009). The same methods were used for testing all the geometries with determining the first layer height for all the models based on Equation 4.

Then, the thickness of the first layer $\Delta \mathrm{s}$ is calculated from:

$$
\Delta s=\frac{y^{+} \mu}{\rho U_{f}}
$$

Where $\mu$ and $\varrho$ are the viscosity and density of the fluid and $U_{f}$ is the frictional velocity, which is defined by:

$$
U_{f}=\sqrt{\frac{\tau_{w}}{\rho}}
$$


$\tau_{w}$ is the wall shear stress and can be calculated from the following equation:

$$
\tau_{w}=\frac{1}{2} C_{f} \rho U_{w}^{2}
$$

Where $C_{f}$ is the skin friction coefficient which can be estimated from the empirical equation $C_{f}=0.058 \mathrm{Re}^{-0.2}$ (Team, 2013).

\section{Boundary Condition}

The same steps used in validation process by Saleh and Husain, 2019, were also applied to prescribe the boundary conditions including the inlet, outlet, openings, walls, and symmetry for all the geometries tested in the current study.

\section{Inlet}

The inlet boundary selected as water inlet with four different velocities and water depth to meet the desired flow discharges which lies is between $1 \leq \mathrm{d}_{\mathrm{c}} / \mathrm{h}_{\mathrm{s}} \leq 2.2$, in which $d_{c}$ is the critical flow depth on the crest and $h_{s}$ is the step height.

\section{Outlet}

For outlet boundary, the relative air pressure is adapted and selected as static pressure with 0pa.

\section{Opening}

The top section of the geometries set as free-surface with no pressure or atmospheric pressure.

\section{Walls}

The bed of all of the geometries set as walls with stationary and no-slip condition.

\section{Symmetry}

For reducing the computational time, the symmetry was chosen.

\section{Turbulence Mode}

In this research, the RNG k- $\varepsilon$ turbulence model supported by ANSYS-CFX was applied (Li and Zhang, 2018) because the accuracy of the output results of this type of turbulence model is reasonable.

\section{RESULTS AND DISCUSSION}

In this research, 32 models are run to determine the effect of a number of parameters including flow discharge, chute slope, and step heights on the free-surface profile over non-uniform step height spillways. Furthermore, the fractional volume of water $\alpha_{w}=0.5$ is utilized for estimating the free-surface distribution as it was used by Turan et al., 2007, Albadawi et al., 2013, Witt et al., 2015, and provided accurate computational results.

The snapshot of contour line of water surface and the velocity vector are achieved by ANSYS-CFX code shown in Figure 3 for configuration A, chute slopes $(1 \mathrm{~V}: 2 \mathrm{H}$ and $1 \mathrm{~V}: 2.5 \mathrm{H})$ and $\mathrm{q}=0.2313 \mathrm{~m}^{2} / \mathrm{s}$. It can be noticed that large

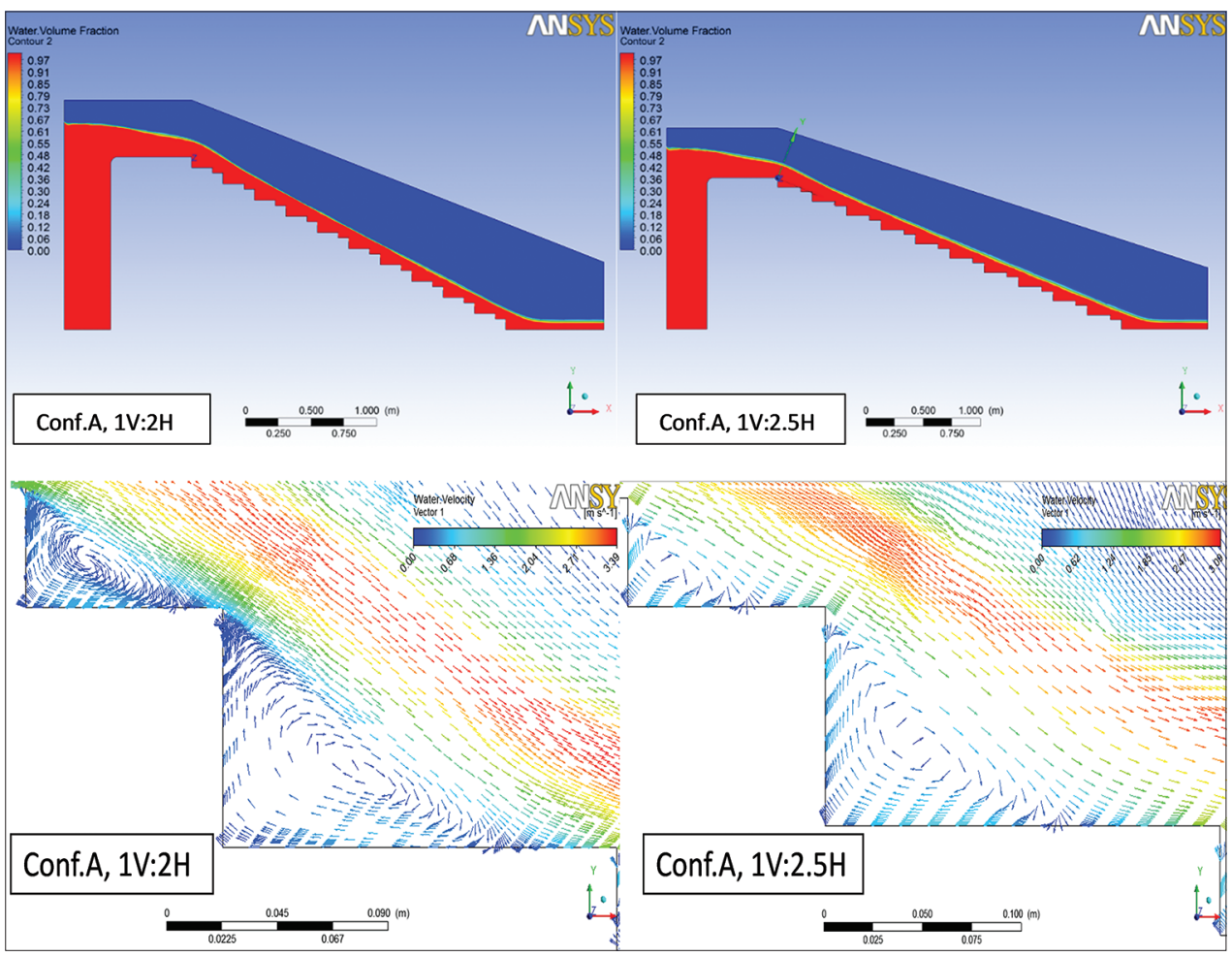

Figure 3: Snapshot of water volume fraction and velocity vector for configuration A 
recirculating cavities are produces when water pass through the steps and rotate as a triangular vortex.

Figure 4 plots the free-surface profile defined in terms of the equivalent water depth $\mathrm{d}$ predicted by ANSYS-CFX at different locations $\mathrm{x}$ measured from the end of the crest over the chute slope $1 \mathrm{~V}: 2 \mathrm{H}$ of the step configuration $\mathrm{A}$ for all discharges examined in this study. As it is appeared in this figure, the free-surface profile of the flow over stepped spillway is of wavy and fluctuated pattern, especially with

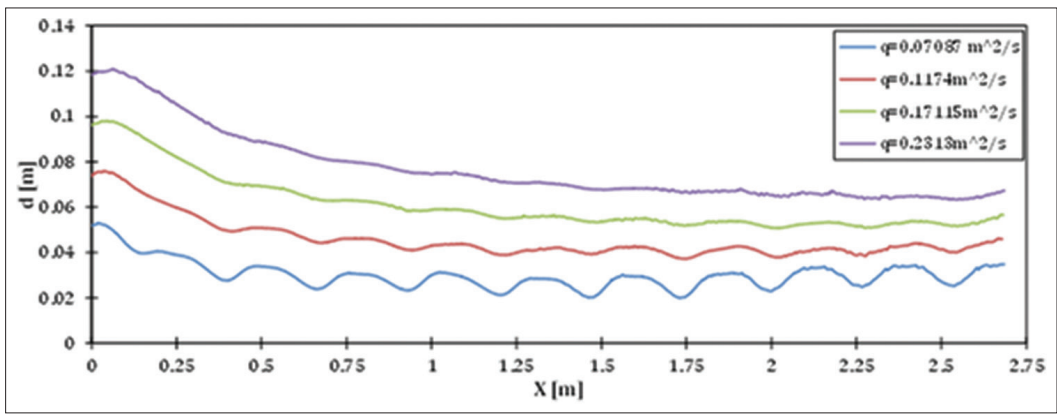

Figure 4: Water surface profile over non-uniform stepped spillway, configuration A, slope $26.6^{\circ}$
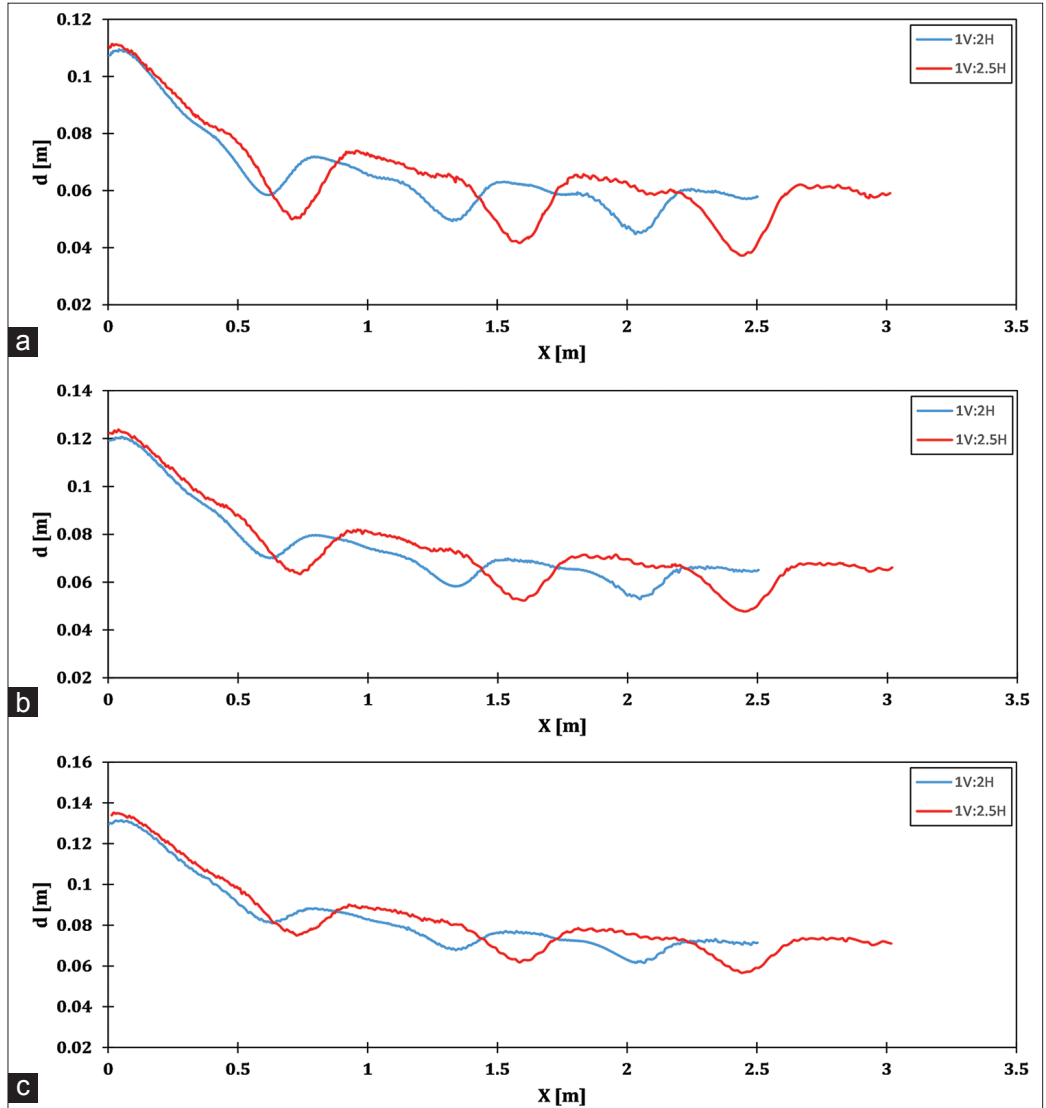

c

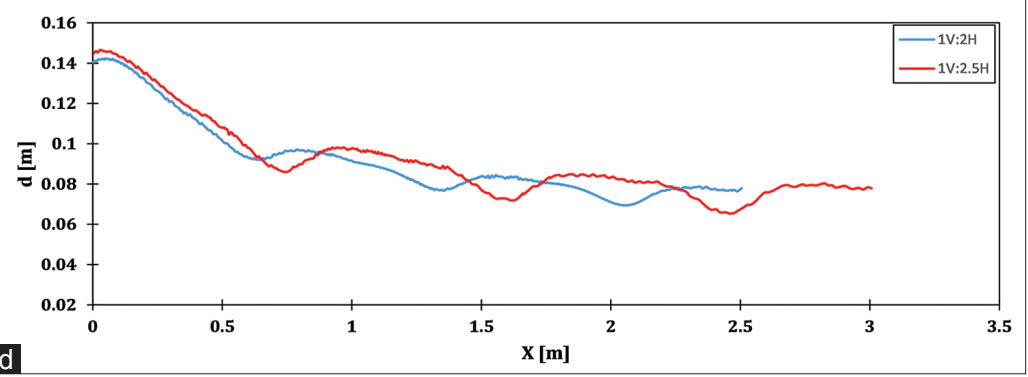

Figure 5: Water surface profile over non-uniform stepped spillway, configuration C, for two chute slopes $1 \mathrm{~V}: 2 \mathrm{H}$ and $1 \mathrm{~V}: 2.5 \mathrm{H}$, for discharge (a) $q=0.2 \mathrm{~m}^{2} / \mathrm{s}$, (b) $q=0.2312 \mathrm{~m}^{2} / \mathrm{s}$, (c) $q=0.263 \mathrm{~m}^{2} / \mathrm{s}$, (d) $q=0.297 \mathrm{~m}^{2} / \mathrm{s}$ 


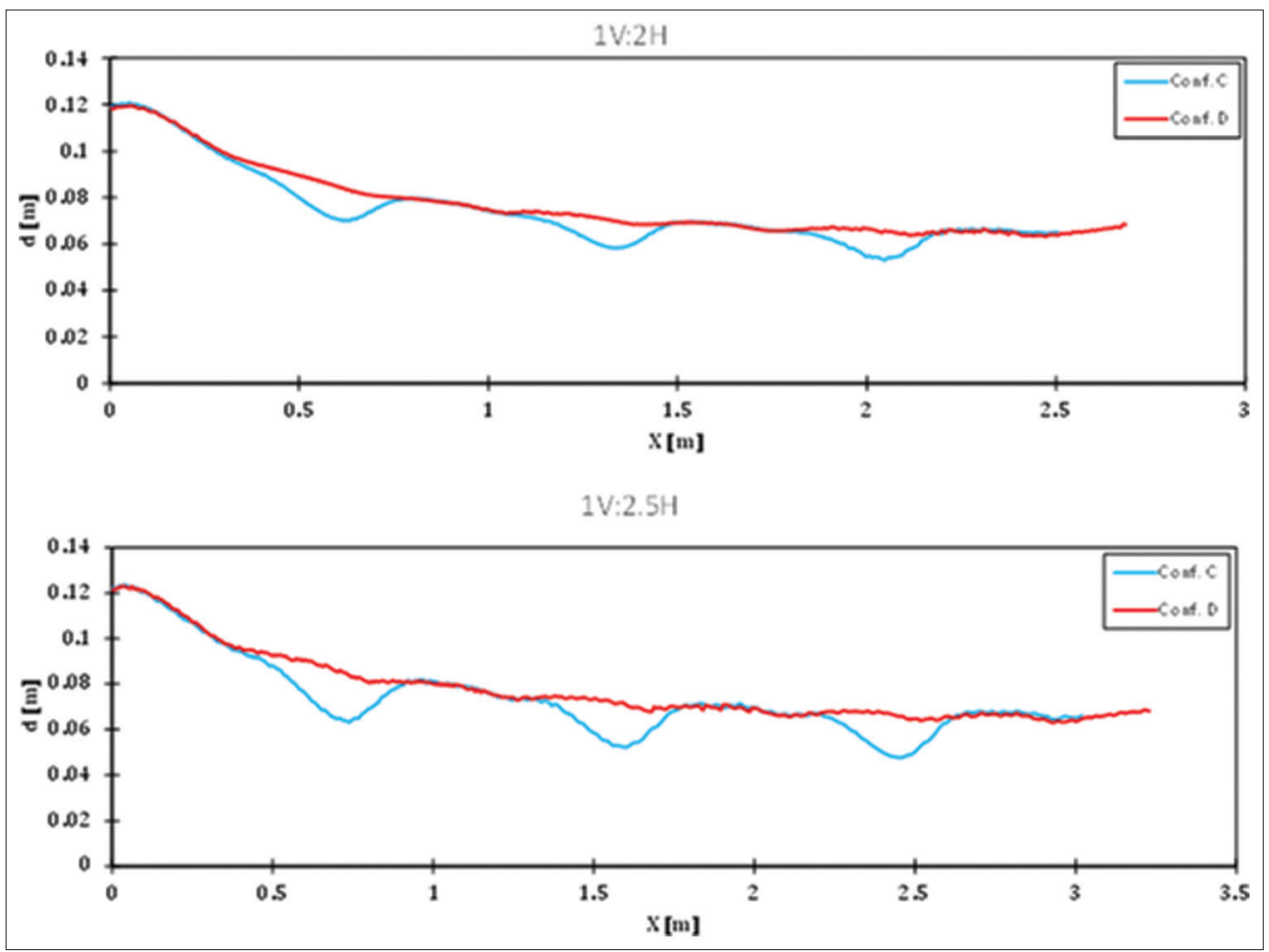

Figure 6: Water surface profile over non-uniform stepped spillway, configurations $C$ and $D, q=0.2313 \mathrm{~m}^{2} / \mathrm{s}$

low discharges. However, with considerable reduction in fluctuation can be observed as the flow discharge is increased. Further, as it can be seen higher free-surface profile is associated with the larger flow discharge. This agrees with those described by Matos et al., 1999, Lucio, 2015, for free-surface profile over stepped spillway.

To find how the slope influences, the free-surface profile over non-uniform stepped spillway Figure 5 is depicted for configuration $\mathrm{C}$. The result shows that the depth of flow is increased with the decrease of the chute slope. This can be justified on the ground that for the same discharge the velocity of flow is larger for steeper slope and hence the flow depth is decreased (Chow, 1959, Chanson, 2002, Husain, 2013). Boes and Hager, 2003a, pointed out that the spillway slope has great influence on the equivalent clear depth.

Different step heights are tested in the current study to understand the effect of step height on the depth of flow. Figure 6 presents the free-surface profile over step configurations $\mathrm{C}$ and $\mathrm{D}$ for a flow discharge of $\mathrm{q}=0.2313 \mathrm{~m}^{2} / \mathrm{s}$. According to this figure changing, the step height is insignificant in raising the water surface profile over non-uniform stepped spillway.

\section{CONCLUSION}

The numerical software package ANSYS-CFX is utilized to measure the free-surface profile over non-uniform stepped spillway. For this purpose, eight configurations of two slopes (1V:2H and $1 \mathrm{~V}: 2.5 \mathrm{H})$ and four flow discharges with range of $\mathrm{d}_{\mathrm{c}} / \mathrm{h}_{\mathrm{s}}$ from 1 to 2.2 are tested. The freesurface profile shows wavy pattern over stepped spillway, although the waves reduce as the flow rate increases. For the same flow discharge, the velocity of flow increases for steeper slopes and the flow depth decreases. Hence, the depth of flow has an inverse relation with the chute slope. Furthermore, it is concluded that the step height might not affect the flow depth over such hydraulic structure. The results obtained in the current work provide new insight into the design of stepped spillways using the non-uniform step height spillways. However, more studies are needed to be carried out to find how it affects the pressure distribution and energy dissipation rate to compare its performance with the horizontal inclined steps.

\section{REFERENCES}

Albadawi, A., D. Donoghue, A. Robinson, D. Murray and Y. Delauré. 2013. Influence of surface tension implementation in volume of fluid and coupled volume of fluid with level set methods for bubble growth and detachment. Int. J. Multiph. Flow. 53: 11-28.

André, S. and A. Schleiss. 2004. High Velocity Aerated Flows on Stepped Chutes with Macro-Roughness Elements. EPFL-LCH.

Bentalha, C. and M. Habi. 2019. Free surface profile and inception point as characteristics of aerated flow over stepped spillway: Numerical study. J. Water Land Dev. 42: 42-48.

Boes, R. M and W. H. Hager. 2003a. Hydraulic design of stepped spillways. J. Hydraul. Eng. 129: 671-679. 
Boes, R. M. and W. H. Hager. 2003b. Two-phase flow characteristics of stepped spillways. J. Hydraul. Eng. 129: 661-670.

Bombardelli, F. A., I. Meireles and J. Matos. 2011. Laboratory measurements and multi-block numerical simulations of the mean flow and turbulence in the non-aerated skimming flow region of steep stepped spillways. Environ. Fluid Mech. 11: 263-288.

Chakib, B. and H. Mohammed. 2015. Numerical simulation of air entrainment for flat-sloped stepped spillway. J. Comput. Multiph. Flows. 7: 33-41.

Chamani, M. R. 1998. Skimming flow in a large model of a stepped spillway. Environ. Fluid Mech. 17(2): 303-322.

Chanson, H. 1994. Hydraulics of skimming flows over stepped channels and spillways. J. Hydraul. Res. 32: 445-460.

Chanson, H. 1996. Prediction of the transition nappe/skimming flow on a stepped channel. J. Hydraul. Res. 34: 421-429.

Chanson, H. 1998. Review of Studies on Stepped Channel Flows. Workshop on Flow Characteristics around Hydraulic Structures and River Environment, Nihon University, Tokyo, Japan.

Chanson, H. 2002. Hydraulics of Stepped Chutes and Spillways. CRC Press, Boca Raton, Florida.

Chinnarasri, C. and S. Wongwises. 2004. Flow regimes and energy loss on chutes with upward inclined steps. Can. J. Civil Eng. 31: 870-879.

Chow, V. T. 1959. Open-channel Hydraulics. McGraw-Hill Education, New York, New York.

Felder, S. 2013. Air-Water Flow Properties on Stepped Spillways for Embankment Dams: Aeration, Energy Dissipation and Turbulence on Uniform, Non-uniform and Pooled Stepped Chutes.

Gonzalez, C. A. 2005. An Experimental Study of Free-surface Aeration on Embankment Stepped Chutes. In: Presented as a Thesis to the University of Queensland for the degree of Doctor of Philosophy.

Husain, S. M. 2013. Computational Investigation of Skimming Flow on Stepped Spillways Using the Smoothed Particle Hydrodynamics Method. Swansea University, United Kingdom.

Husain, S. M., J. R. Muhammed, H. U. Karunarathna and D. E. Reeve. 2014. Investigation of pressure variations over stepped spillways using smooth particle hydrodynamics. Adv. Water Resour. 66: 52-69.

Jalil, S. A. and B. S. Hussein. 2017. Experimental and modeling of flow over labyrinth and plain stepped falls. J. Duhok Univ. 20(1): 662-679.
Khalaf, R. M., R. H. Irzooki and S. J. Shareef. 2014. Flow characteristics and energy dissipation over traditional and stepped spillway with semicircular crest. Int. J. Civil Environ. Eng. 14(2): 13-27.

$\mathrm{Li}, \mathrm{S}$ and J. Zhang. 2018. Numerical investigation on the hydraulic properties of the skimming flow over pooled stepped spillway. Water. 10: 1478.

Lucio, I. S. A. 2015. Numerical modeling of skimming flow over stepped spillways: Application on small embankment dams. Instituto Superior Tecnico, Lisbon!.

Matos, J., M. Sanchez, A. Quintela and J. Dolz. 1999. Characteristic Depth and Pressure Profiles in Skimming Flow Over Stepped Spillways. Proceedings of the $29^{\text {th }}$ IAHR Congress, Graz, Austria.

Saleh, S. M. and S. M. Husain. 2019. Validation of the computational ANSYS-CFX code for free surface flow: Skimming flow over non-uniform step size stepped spillways. ZANCO J. Pure Appl. Sci. 31: 361-367.

Salim, S. M., S. Cheah and Y. Wall. Strategy for dealing with wallbounded turbulent flows. Proceedings of the international multiconference of engineers and computer scientists Conference: International Multi Conference of Engineers and Computer Scientists, IMECS 2009.

Tabbara, M., J. Chatila and R. Awwad. 2005. Computational simulation of flow over stepped spillways. Comput. Struct. 83: 2215-2224.

Team, L. C. 2013. Tips and tricks: Estimating the first cell height for correct Y+. Leap Australia Computational Fluid Dynamics Blog (CFD). Available from: https://www.computationalfluiddynamics. com.au/tips-tricks-cfd-estimate-first-cell-height. [Last accessed on 2013 Jul 01].

Turan, C., M. Politano, P. Carrica and L. Weber. 2007. Water entrainment due to spillway surface jets. Int. J. Comput. Fluid Dyn. 21: 137-153.

Valero, D. and D. B. Bung, D. B. 2015. Hybrid Investigations of Air Transport Processes in Moderately Sloped Stepped Spillway Flows. E-Proceedings of the $36^{\text {th }}$ IAHR World Congress.

Van Alwon, J., D. Borman, A. Sleigh and N. Kapur. 2017. Experimental and Numerical Modelling of Aerated Flows Over Stepped Spillways. Proceedings of IAHR 2017 International Association for Hydro-Environment Engineering and Research.

Witt, A., J. Gulliver and L. Shen. 2015. Simulating air entrainment and vortex dynamics in a hydraulic jump. Int. J. Multiph. Flow. 72: $165-180$. 